\title{
Inverse Chill in Cast Iron
}

\author{
By R. D. Bhavsar*, Ding Hui* and R. W. Smith*
}

\begin{abstract}
The occurrence of white iron in the interior of otherwise gray casting and a gray surface rim in a nominally white iron casting is contrary to general expectations. These phenomena, called inverse chill and inverse grayness respectively, affect cast metal quality and have important practical consequences. Hence, the sometimes conflicting published data was examined and a number of experiments were carried out to evaluate the apparent anomalies, using vacuum-refined, highly pure synthetic and commercial (Sorel F-10, S-125) Fe-C-Si alloys. The effects of various foreign elements on the formation of inverse chill were also studied by adding them singly in a highly pure form to the vacuum-refined alloys. Measurements of the cooling rates were made at the centre and top and bottom surfaces of the solidifying ingot to verify the relationship between the differential cooling rate and inverse chill.

Argon, oxygen, hydrogen and sulphur were found to be critical to the formation of inverse chill (occurrence of carbides). This study indicated that inverse chill can result from: (a) slow growth of nodules; (b) segregation of carbide-stabilizing elements towards the centre; (c) reduction of the carbon equivalent value, mainly by a reduction in silicon content; (d) the presence of oxygen or argon in the melt.
\end{abstract}

(Received June 18, 1987)

Keywords: cast iron, gray iron, white iron, carbides, inverse chill, vacuum-refining, flake graphite, coral graphite, compacted graphite, nodular graphite

\section{Introduction}

It is well-known that the solidification mode of cast iron depends on the nucleation frequency and growth rates of the cementite $\left(\mathrm{Fe}_{3} \mathrm{C}\right)$ and graphite phases. The equilibrium temperature for the iron-cementite $\left(\mathrm{Fe}-\mathrm{Fe}_{3} \mathrm{C}\right)$ eutectic is about $6 \mathrm{~K}$ lower than that of irongraphite (Fe-C) eutectic. Thus, if the interface temperature falls below the cementite eutectic temperature, then a white iron usually is the result.

The structure of cast iron is greatly influenced by the undercooling which can be promoted by superheating the melt, by alloying additions, by impurities or by rapid cooling. Some elements present in cast iron as impurities, such as $\mathrm{Mn}$ and $\mathrm{Cr}$, encourage the formation of white iron by stabilizing the cementite, whilst other elements such as $\mathrm{Si}, \mathrm{Ni}$, $\mathrm{Cu}$ promote the formation of graphite by decreasing the stability of cementite.

Below $1420 \mathrm{~K}\left(1147^{\circ} \mathrm{C}\right)$, the $\mathrm{Fe}_{3} \mathrm{C}$ eutectic can form. The growth rate of this eutectic rap-

* Queen's University, Kingston, Ontario, Canada, K7L 3N6. idly exceeds that of the gray iron eutectic as the temperature falls and, at a temperature of approximately $1413 \mathrm{~K}\left(1140^{\circ} \mathrm{C}\right)$, generally there is a change from gray to white iron solidification. In general, carbidic eutectic solidification requires one or more of the following conditions:

(a) a reduction in nucleation frequency of the graphite eutectic,

(b) a reduction in eutectic cell growth rate,

(c) a higher cooling rate, and

(d) less separation of the two eutectic equilibrium temperatures.

The outside of a cast component cools faster than the interior, so that white iron tends to form in the outer part and, if any gray iron is to form at all, it should be present in the interior of the casting. However, frequently white iron is found in the interior of an otherwise gray iron casting and this phenomenon is called 'inverse chill'. A similar phenomenon is the formation of a gray rim on an otherwise white iron casting. This is called 'inverse grayness'.

Earlier work on the subject indicates that inverse chill in gray iron may occur in three forms which are distinguished as:

(a) a sharply defined white core, 
(b) chill at the centres of bars, and

(c) a gray rim around a white or mottled section.

Experiments by Hughes and Oldfield ${ }^{(1)}$ have shown that a sharply defined white core occurs when the following three conditions exist simultaneously:

(a) large unbalanced sulphur-content,

(b) large hydrogen-content, and

(c) small nucleation frequency of the graphite eutectic.

Tsutsumi and Matsukawa ${ }^{(2)}$ and other earlier investigators also observed two forms of inverse chill, namely,

(i) the wide band inverse chill and

(ii) the concentrated inverse chill.

By means of chemical analysis and electron probe microanalysis, it was shown that no detectable segregation had occurred in the wide band inverse chill area. The wide band inverse chill tendency was found to increase with an increase in pouring temperature and a decrease in carbon equivalent value. This can be explained in terms of the effects of undercooling. Mn-segregation was detected in the concentrated inverse chill. Zapffe and Phebus ${ }^{(3)}$ had earlier suggested that inverse chill is caused by the segregation of hydrogen. Although the segregation of alloying elements was considered to be one of the main factors responsible for 'inverse chill' in the early days, this hypothesis could not be confirmed by the chemical analysis techniques available at the time $^{(4)}$.

It is clear that inverse chill has been the cause of much speculation. Since inverse chill may be promoted by a number of factors, it is not surprising that some confusion as to mechanism is present in the literature. In order to eliminate the interference of as many variables as possible and to obtain uniform experimental conditions, the present study of inverse chill was carried out using highly pure synthetic and commercial $\mathrm{Fe}-\mathrm{C}-\mathrm{Si}$ alloys, which were then further purified by a 3-hour vacuum treatment. The effects of reportedly important foreign elements were also studied by adding them successively to the 3-hour vacuum-refined high-purity $\mathrm{Fe}-\mathrm{C}-\mathrm{Si}$ alloys.

\section{Experimental Procedures}

Two types of experimental arrangements were used. For melting small charges $(50 \mathrm{~g})$, a small high frequency induction furnace, capable of rapidly attaining a vacuum of $10^{-4} \mathrm{~Pa}$, was used. In order to obtain a more general view on 'inverse chill', experiments were also conducted in a larger vacuum furnace using 400 to $600 \mathrm{~g}$ charges, evacuable to pressures in the range of $10^{-3}$ to $10^{-4} \mathrm{~Pa}$ in less than two hours. To facilitate continuous observation of the melting and casting processes, the vacuum chambers of both the furnaces were equipped with sight glasses. Temperature was measured and recorded by using three $\mathrm{Pt}-\mathrm{Pt} / 13 \mathrm{Rh}$ thermocouples encased in high purity alumina insulation [Fig. 1].

\section{Alloys}

(a) Hypo- and hypereutectic synthetic cast irons were made from high purity ( $>99.99 \%)$ iron, spectroscopically pure (>99.999\%) graphite and semiconductor grade (>99.9999\%) silicon.

(b) Hypo- and hypereutectic commercial cast irons consisted of the two types of Sorel irons (F-10 and S-125, Table 1). Sometimes graphite $(>99.999 \%)$ and/or silicon ( $>99.9999 \%$ Si) was added to the pig iron used to adjust the carbon equivalent (CE) as required.

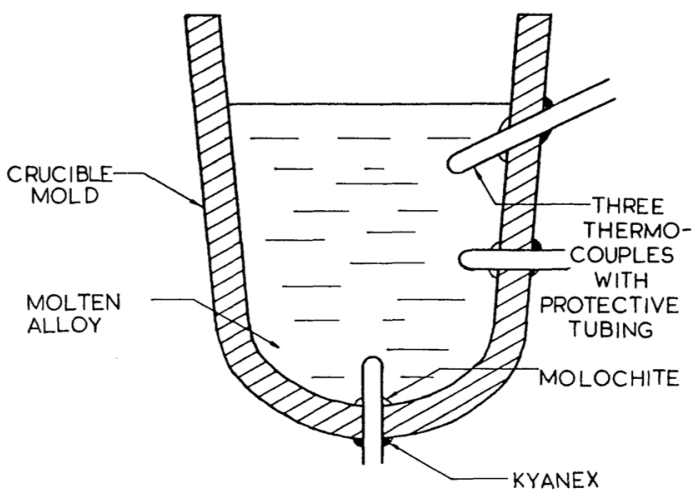

Fig. 1 Schematic view of the crucible-mold, showing the thermocouples (encased in protective tubing) held in the crucible side-walls. 
Table 1 Compositions of Sorel alloys.

\begin{tabular}{lccccc}
\hline \hline Alloy & $\mathrm{C} \%$ & $\mathrm{Si} \%$ & $\mathrm{~S} \%$ & $\mathrm{Mn} \%$ & $\mathrm{P} \%$ \\
\hline F-10 & 4.32 & 0.19 & 0.007 & 0.009 & 0.025 \\
S-125 & 4.02 & 1.46 & 0.009 & 0.009 & 0.027 \\
\hline \hline
\end{tabular}

\section{Additions}

The oxygen, nitrogen and argon used were all dry and of ultra-high purity grade while hydrogen was of a pre-purified grade. Sulphur was added in the form of small lumps of FeS, placed at the bottom of the crucible, under the charge.

\section{Procedure}

The charge was washed in trichloroethylene and acetone and then loaded into the melting crucible. Small standard (LECO) alumina (99.9\% purity) crucibles were employed for the small charges (internal diameter of $25 \mathrm{~mm}$ and a height of $25 \mathrm{~mm}$ ). Zirnorite crucibles (O.D. $=85 \mathrm{~mm}$, I.D. $=62.5 \mathrm{~mm}$ and height $=$ $138 \mathrm{~mm}$ ) supplied by Norton Canada Inc. ( $92 \%$ zirconia plus $\mathrm{Al}_{2} \mathrm{O}_{3}, \mathrm{SiO}_{2}, \mathrm{TiO}_{2}$ and $\mathrm{Fe}$ ) were used for the large charges.

The pressure in the vacuum chamber was reduced to $10^{-3}$ to $10^{-4} \mathrm{~Pa}$ and then the charge was heated to approximately $973-1073 \mathrm{~K}$. This promoted degassing until finally the charge was melted and held under vacuum for three hours except when 'time' was the parameter under investigation or was going to influence the variables being investigated. Then the furnace power was turned off and the melt allowed to freeze in situ in the crucible under vacuum or, in the case of large furnace, cast into a ceramic mold. Under normal conditions, a cooling rate of approximately 0.3 to $0.5 \mathrm{~K} / \mathrm{s}\left(20\right.$ to $30^{\circ} \mathrm{C} / \mathrm{min}$.) was observed in both cases.

Since holding the melt under vacuum for longer than $10.8 \mathrm{ks}(3 \mathrm{~h})$ and/or using more than $300 \mathrm{~K}$ superheat did not appear to induce further microstructural changes, it was decided to adopt these values for the standard vacuum refining treatment before making any chamical additions. In a later series of experiments, $\mathrm{Fe}-$ $\mathrm{C}-\mathrm{Si}$ alloys treated in vacuum for $10.8 \mathrm{ks}$ and with $300 \mathrm{~K}$ superheat were remelted and solidified in situ or cast into a ceramic mold (large furnace) under the following conditons:

(i) vacuum

(ii) air

(iii) argon

(iv) argon-oxygen

(v) argon-nitrogen

(vi) argon-hydrogen

(vii) with sulphur only

(viii) argon-hydrogen and sulphur.

\section{Microscopic examination}

Transverse and longitudinal sections were prepared for optical metallography and examined in the unetched and etched ( $2 \%$ Nital) conditions.

Subsequently, the samples were deep-etched to selectively dissolve the iron-matrix at the surface. This was done by bathing the samples with $10-15 \%$ hydrochloric acid in ethyl alcohol at $343 \mathrm{~K}\left(70^{\circ} \mathrm{C}\right)$ for $10.8-14.4 \mathrm{ks}(3-4 \mathrm{~h})$, depending upon the chemical composition and graphite morphology of the sample. Then the samples were thorougly rinsed with ethanol and acetone, dried and observed in a JEOL T300 scanning electron microscope, using an acceleration voltage of $20 \mathrm{kV}$.

\section{Results}

Initially, when a few experiments were carried-out on Sorel iron $(\mathrm{F}-10) \mathrm{Si}=0.19 \%, \mathrm{C} . \mathrm{E}$. $=4.38 \%$ ) without any addition of silicon, an entirely white iron structure was obtained for all the experiments (Fig. 2). Then a sufficient quantity of silicon was added to Sorel iron (F10) to produce a C.E. of $4.82 \%$, and the holding time and the degree of superheat were varied separately. The effect of an increase in holding time was found to be approximately the same as an increase in superheat, namely, the proportion of undercooled (D-type) graphite was observed to decrease while the proportion of coral and compacted graphite increased.

The results obtained for synthetic alloys were almost similar to commercial (Sorel) alloys after vacuum treatment. Also it was observed that, in general, the results obtained for the small melt-ingots were mirrored by 


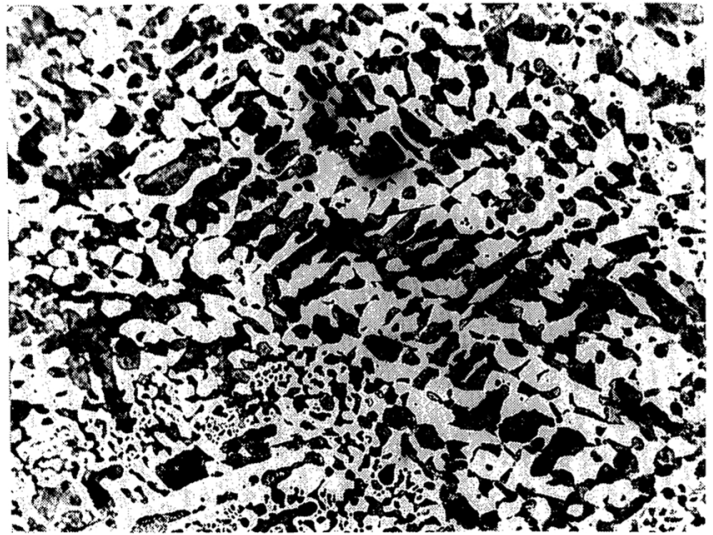

Fig. 2 Hypereutectic commercial alloy, Sorel iron (F-10), as-received, without any addition, (C.E. $=4.38, \mathrm{C}=$ $4.32 \%, \mathrm{Si}=0.19 \%)$, vacuum-refined for $10.8 \mathrm{ks}(3 \mathrm{~h})$ with a superheat of $300 \mathrm{~K}$. Etched $2 \%$ Nital, $(\times 100 \times 3 / 5)$. Entirely white iron structure throughout the ingot.

those from the large melt-ingots prepared under similar conditions. Small variations in microstructure were observed but these were of no greater significance than the variations in equivalent positions in any ingot cross-section.

Typical results obtained after vacuum-refining a commercial (C.E. $=4.82 \%$ ) Sorel alloy and a synthetic (C.E. $=3.8 \%)$ alloy for $10.8 \mathrm{ks}$ with a superheat of $300 \mathrm{~K}$ are shown in photomicrographs in Fig. 3(a) and (b) respectively.

A number of hypereutectic alloys (commercial Sorel iron, F-10, with the addition of silicon to produce a C.E. of $4.82 \%$, Sorel iron, $\mathrm{S}-125$, as received with the C.E. $=4.5 \%$, synthetic irons with a C.E. of $4.8 \%$ ) were all given the standard vacuum-refining treatment and then allowed to freeze, as noted earlier, under various atmospheres or after the introduction of sulphur as iron sulphide. Similar results were obtained for all three alloys. These results are discussed into details in Refs. (31) and (32). Some of the important features of the results are discussed here in this paper.

(i) Air: When a hypereutectic Sorel alloy, treated in vacuum for $10.8 \mathrm{ks}$ with a superheat of $300 \mathrm{~K}$, was remelted in air and allowed to freeze in the crucible (small charge); the microstructure was found to consist mainly of irregular graphite lumps (nodules) embeded in

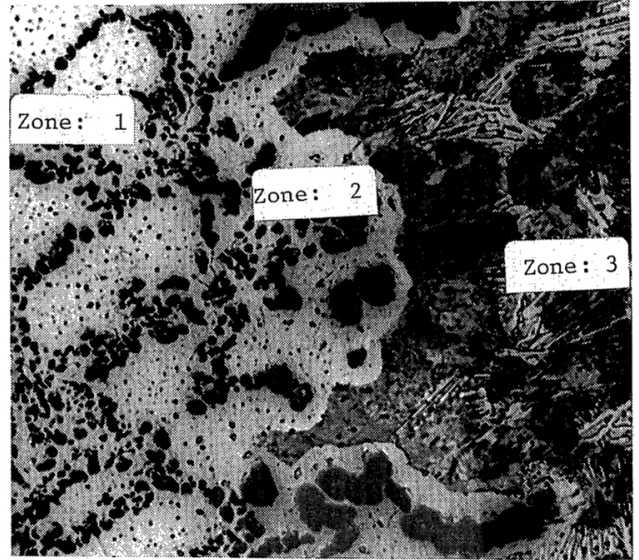

Fig. 3(a) Hypereutectic commercial alloy, Sorel iron (F10 ), with the addition of $1.31 \%$ pure Si (C.E. $=4.82 \%$, $\mathrm{C}=4.32 \%, \mathrm{Si}=1.50 \%$ ), vacuum-refined for $10.8 \mathrm{ks}$ with a superheat of $300 \mathrm{~K}$.

Etched $2 \%$ Nital, $(\times 220 \times 2 / 3)$.

Zone 1: coral graphite in a ferritic matrix.

Zone 2: compacted graphite in a ferritic matrix.

Zone 3: white iron.

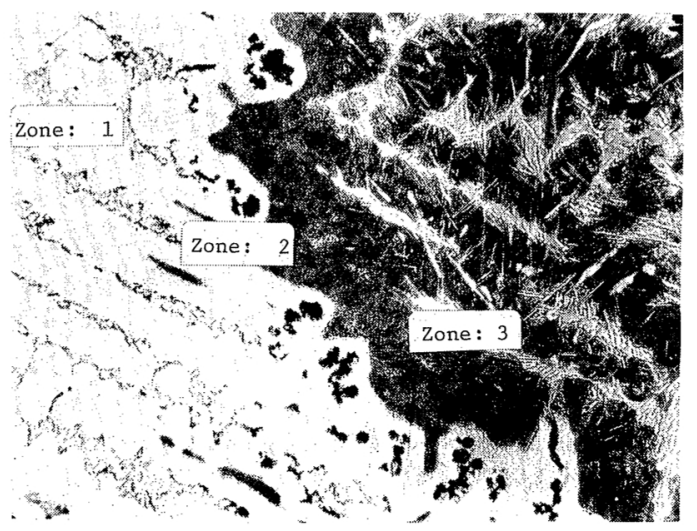

Fig. 3(b) Hypoeutectic synthetic (Fe-C-Si) alloys. (C.E. $=3.8 \%, \mathrm{Fe}=94.6 \%, \mathrm{C}=3.0 \%, \mathrm{Si}=2.4 \%$ ), vacuumrefined for $10.8 \mathrm{ks}$, with a superheat of $300 \mathrm{~K}$. Etched $2 \%$ Nital, $(\times 150 \times 3 / 5)$.

Zone 1: coral graphite in a ferritic matrix.

Zone 2: compacted graphite in a ferritic matrix. Zone 3: white iron.

a pearlitic/ledeburitic matrix in the major central/intermediate potion of the ingot, Fig. 4(a).

(ii) Argon: A similar treatment i.e. remelting and solidification under argon atmosphere after vacuum purification for $10.8 \mathrm{ks}$ with a superheat of $300 \mathrm{~K}$, produced a microstructure consisting mainly of compacted graphite along with a random distribution of 


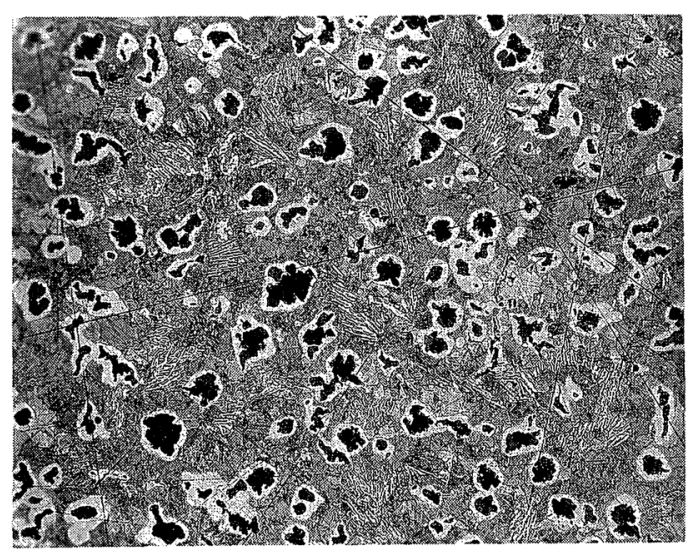

Fig. 4(a) Hypereutectic commercial alloy, Sorel iron (F$10)$, with the addition of $1.31 \%$ pure $\mathrm{Si}$ (C.E. $=4.82 \%$, $\mathrm{C}=4.32 \%, \mathrm{Si}=1.5 \%$ ), remelted in air after vacuumpurification for $10.8 \mathrm{ks}$ with a superheat of $300 \mathrm{~K}$. Etched $2 \%$ Nital, $(\times 220 \times 3 / 5)$. Zone 2: Graphite lumps (nodular and compacted) in a pearlitic/ ledeburitic matrix.

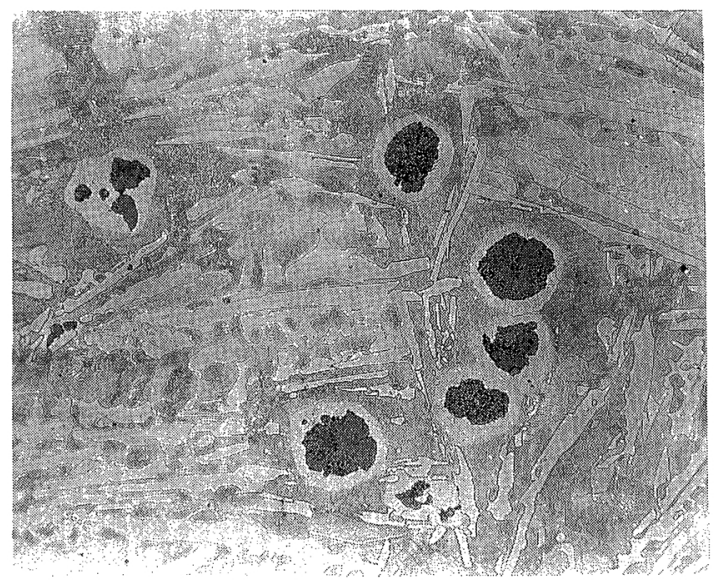

Fig. 4(b) Hypereutectic commercial alloy, Sorel iron (F$10)$, with the addition of $1.31 \%$ pure $\mathrm{Si}$ (C.E. $=4.82 \%$, $\mathrm{C}=4.32 \%, \mathrm{Si}=1.50 \%$ ), remelted in vacuum after 10.8 ks of vacuum purification. Etched $2 \%$ Nital, $(\times 220 \times 2 / 3)$. Perfect and imperfect spheroids of graphite in a ledeburitic matrix.

carbides. The microstructural appearance was similar to that in Figs. 5 and 6(a).

(iii) Oxygen: A similar treatment in this case produced a microstructure with mainly A and D-type flakes of graphite in an almost fully pearlitic matrix. Many carbides were present throughout the ingot, but the major occurrence was localized in the central zone, Fig. 5.

(iv) Hydrogen and sulphur: In this case,

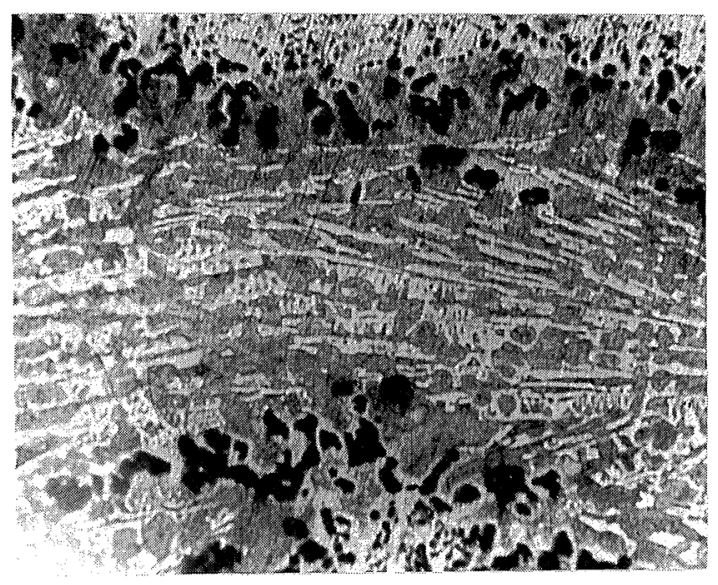

Fig. 5 Hypereutectic commercial alloy, Sorel iron (F-10), with the addition of $1.31 \%$ pure $\mathrm{Si}$ (C.E. $=4.82 \%$, $\mathrm{C}=4.32 \%, \mathrm{Si}=1.5 \%$ ), remelted under argon-oxygen atmosphere after vacuum-purification for $10.8 \mathrm{ks}$ with a superheat of $300 \mathrm{~K}$. Etched $2 \%$ Nital, $(\times 220 \times 3 / 5)$. Coarsened/compacted graphite surrounding the carbides.

the interdendritic graphite was present mainly in the form of a network of mesh-like/thorny, short and medium A-type flakes and small lumps in a predominantly pearlitic matrix, but there was no evidence of carbides throughout the ingot.

(v) Various additions were made to the Sorel iron (S-125) to vary the C.E. from 3.6 to $5 \%$ at four different levels to study the effect of C.E. value and Si on 'inverse chill'. The ingots with C.E. values of $4.1 \%$ and $5 \%$ (without any addition of extra silicon) exhibited invariably small amounts of carbides in the central zones, Fig. 6(a) and (b) respectively. In contrast, the ingots with C.E. values of $3.6 \%, 3.9 \%$ and even $5 \%$ (but with the addition of extra silicon) showed no evidence of carbides. Particularly, the microstructures of the ingots having C.E. values of $5 \%$ without extra silicon [Fig. 6(b)] and with extra silicon [Fig. 6(c)] should be noted.

(vi) One of the factors mentioned in the literature and believed to be responsible for the phenomenon of 'inverse chill' is the differential (inversion of the) cooling rate i.e. the occurrence of a larger cooling rate at the centre than that at the surface. To examine this as a possible cause, thermal analysis was carried-out in 


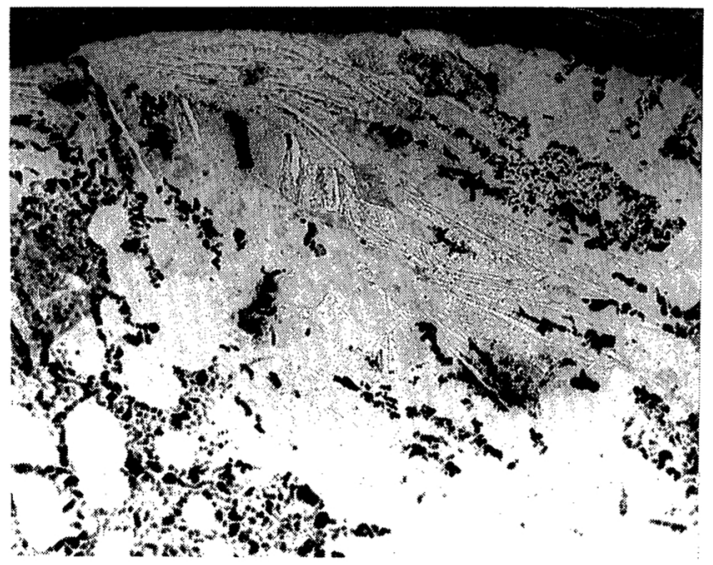

Fig. 6(a) Hypoeutectic commercial alloy, Sorel iron (S125 ), with the addition of pure iron (C.E. $=4.1 \%, \mathrm{C}=$ $3.618 \%, \mathrm{Si}=1.46 \%$ ), vacuum-refined for $1.8 \mathrm{ks}$ with a superheat of $300 \mathrm{~K}$. Etched $2 \% \mathrm{Nital},(\times 150 \times 3 / 5)$. Interdendritic fine compacted and coral graphite in a mainly ferritic matrix and carbides in the top central zone.

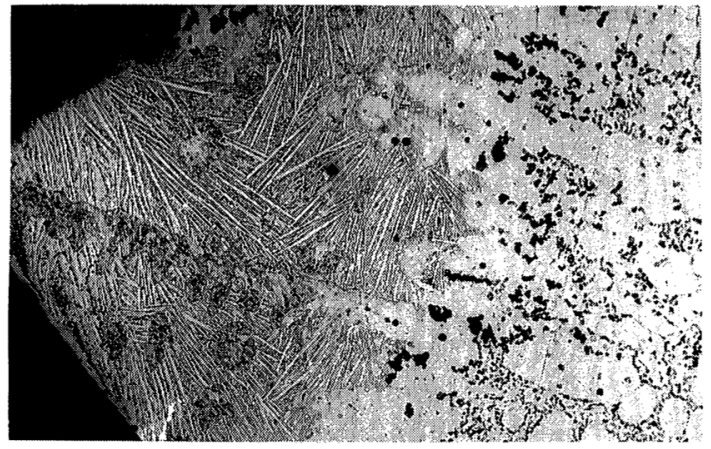

Fig. 6(b) Hypereutectic commercial alloy, Sorel iron (S125 ), with the addition of pure graphite (C.E. $=5.0 \%$, $\mathrm{C}=4.5 \%, \mathrm{Si}=1.46 \%$ ), vacuum-refined for $10.8 \mathrm{ks}$ with a superheat of $300 \mathrm{~K}$. Etched $2 \%$ Nital, $(\times 150 \times 3 / 5)$. A mixture of interdendritic compacted graphite and coral graphite in a mainly ferritic matrix, along with the coarsened graphite surrounding carbides in the central zone.

order to determine whether the various positions of an ingot solidified at similar rates and temperatures were similar. For this, three holes of approximately $4.17 \mathrm{~mm}$ diameter were drilled in the side wall an the bottom of the crucible-mold for inserting thermocoupletips into the solidifying melt, Fig. 1. Thermocouples within the protective tubing were held in place in the crucible-mold wall by the application of "molochite" from inside and

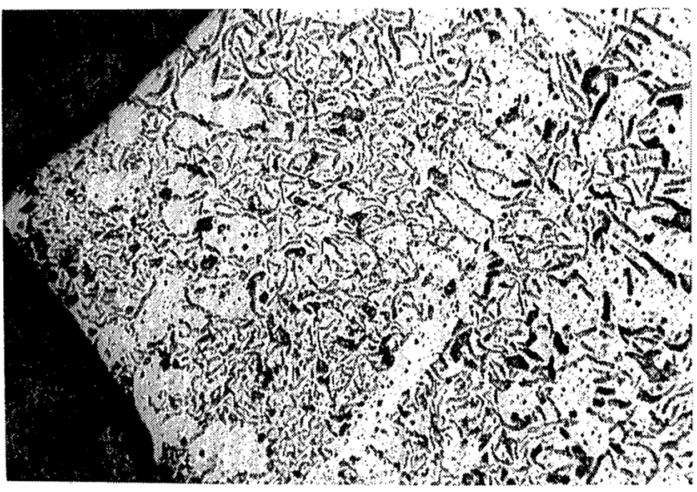

Fig. 6(c) Hypereutectic commercial alloy, Sorel iron (S$125)$, with the addition of pure iron $\mathrm{Si},($ C.E. $=5.0 \%$, $\mathrm{C}=4.02 \%, \mathrm{Si}=3.0 \%$ ), vacuum-refined for $10.8 \mathrm{ks}$ with a superheat of $300 \mathrm{~K}$. Etched $2 \%$ Nital, $(\times 150 \times 3 / 5)$. Well-formed, thick compacted graphite in a mainly ferritic matrix with no sign of carbides.
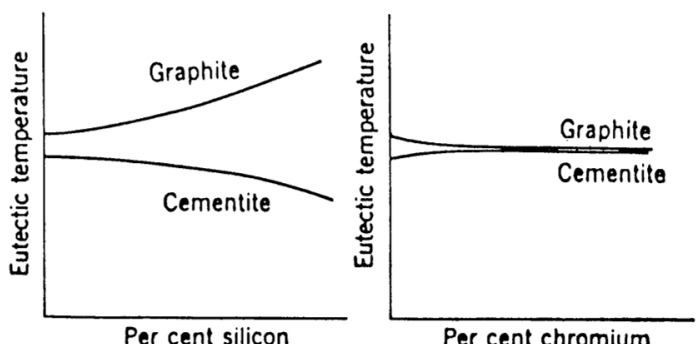

Fig. 6(d) Effect of a third component on the eutectic temperature (schematic) (a) silicon-type (b) chromium-type. From: B. Chalmers, Principles of Solidification, 1st Ed., John Wiley and Sons Ltd., New York, (1964), 220.

"kyanex" from outside. This was considered to be an important procedure and most easily achieved when using the large (Balzers) vacuum furnace. In all of these experiments, temperatures and cooling curves were recorded at the centre and top and bottom surfaces of the solidifying ingot to verify the relationship between the differential cooling rate and inverse chill.

In most of the experiments, cooling curves obtained at the three above-mentioned locations were very similar, suggesting that the differential cooling rates are not significant in producing inverse chill, at least in small ingots of the size used in the present study.

In passing, it should be pointed out that, to indicate the occurrence of carbides in the central zone of an ingot, the micrographs were in- 
tentionally taken with the concentration at the central zone of a sectioned ingot even though some bakelite (sample-mounting material) was included in the micrograph. This bakelite is seen as dark portion in the various micrographs. Micrographs in Fig. 6(a), (b) and (c) may be noted in this context.

\section{Discussion}

\section{Silicon}

The microstructural observations in the present study clearly indicate that Si promotes the formation of graphite, presumably by decreasing the stability of cementite. For instance, hypereutectic Sorel iron (F-10, C.E. $=4.32 \%$ ), when vacuum-refined for $10.8 \mathrm{ks}$ with a superheat of $300 \mathrm{~K}$ without any addition of $\mathrm{Si}$ (small furnace), produced entirely white iron in its microstructure, Fig. 2. The same Sorel iron with the addition of $1.31 \% \mathrm{Si}$, produced some gray iron portion, Fig. 3(a). Similarly, as the Fig. 6(b) indicates, Sorel (S-125) iron without the addition of extra Si (the C.E. was increased in this case by the addition of graphite) produced an ingot with a microstructure consisting of carbides at the centre (inverse chill). As the Fig. 6(c) indicates, the carbides (inverse chill) in this alloy were eliminated just by the addition of $1.56 \% \mathrm{Si}$ i.e. by producing a C.E. of $5 \%$ by increasing $\mathrm{Si}$ instead of C.

These results confirm the much stronger effect of $\mathrm{Si}$ as a graphitizer, as compared to carbon $^{(5)-(8)}$. The literature indicates that silicon significantly alters the eutectic composition and the maximum solubility of carbon in austenite and also the eutectoid composition. $\mathrm{Si}$ limits the area of austenite stability and shifts the eutectoid point to a lower carboncontent and to a higher temperature range. Figure 6(d) delineates the conditions (with respect to Si-content) under which carbon precipitates as graphite and as iron-carbide. The temperature interval between $T_{\mathrm{G}}$ and $T_{\mathrm{Fe}_{3} \mathrm{C}}$ is an increasing function of Si-content. The graphitizing effect of $\mathrm{Si}$ has been explained on the basis of the heterogeneous nucleation theory according to which an increase in the number of nucleating particles reduces the degree of undercooling.

Oldfield $^{(7)}$ studied the effect of Si-content and found that the permanent effect of $\mathrm{Si}$, as opposed to its transient inoculating effect, is due to a reduction in the tendency to chill formation by increasing the difference between $T_{\mathrm{G}}$ and $T_{\mathrm{Fe}_{3} \mathrm{C}}$. Thielemann and Roder ${ }^{(9)}$ carried out $\mathrm{X}$-ray microanalytical investigation of inverse chill in cast iron and found a significant reduction of the Si-content in areas of inverse chill as compared to surrounding gray areas.

\section{Carbon}

The literature ${ }^{(10)-(12)}$ indicates that reducing the C.E. value should increase chilling tendency. In the present study, some of the experiments carried-out in this regard, produced some evidence of carbides in the matrix, Fig. 6(a) but, overall, carbon did not show any significant or conclusive effect on the susceptibility to inverse chill.

\section{Argon}

With the introduction of argon, randomly distributed carbides were observed consistently in the ferritic matrix. A more recent study by Okamoto et al. ${ }^{(13)}$ on the effect of argon pressure indicates that the argon pressure can have a considerable effect on chill formation which could result, as expected from Le Chatelier's principle, in the formation of inverse chill. In view of this and the present results, a systematic investigation of the effect of argon pressure on inverse chill would appear to have merit.

\section{Oxygen}

The results of the observation of carbides are in agreement with several published reports. The use of oxidized iron, iron with high oxygen-content such as poor or rusty scrap, damp launders and ladles, gassy metal, rising feeder heads and porosity in castings were early suggested causes of inverse chill, but even more recent work indicates the importance of oxygen in iron (Fig. 5).

\section{Hydrogen and sulphur}

It should be emphasized that in almost all 
the experiments in the present study with the additions of hydrogen and sulphur (singly and together) there was no evidence of carbides in the resulting microstructure. This observation is not in agreement with some of the reports in the literature $\mathrm{e}^{(3)(14)-(17)}$. Many investigators ${ }^{(16)}$ have suggested that hydrogen itself is responsible for inverse chill, while others ${ }^{(17)}$ have suggested that a high and unbalanced sulphur content is a major contributing cause and they have also demonstrated the combined effects of sulphur and hydrogen in stabilizing the occurrence of white iron eutectic. Both a large unbalanced sulphur content and a large hydrogen content might have the effect of suppressing the solidification of the graphite eutectic because they reduce the growth rate of eutectic cells and lead to greater undercooling, thereby causing ledeburite-formation. The conditions of bad/rusty scrap, damp ladles, launders or moisture from the mold, discussed earlier for oxygen, have been suggested to be much more characteristic of hydrogen than of oxygen in the metal. However, as mentioned earlier, there are a number of ways in which inverse chill structure can occur and it can appear and disappear quite suddenly without the cause being known. This fact seems to have led to confusion in the literature and hence, it may be informative to carry out more systematic experimentation with hydrogen and sulphur to establish a better quantitative relationship, determining the exact amount of these elements at which inverse chill does occur in the vacuum-refined, high purity $\mathrm{Fe}-\mathrm{C}-\mathrm{Si}$ alloys for given cooling conditions.

\section{Differential cooling}

There are reports in the literature ${ }^{(18)-(20)}$ regarding the inversion of cooling rate. Ostberg $^{(18)(19)}$ was able to show that the surface zone could cool more slowly through a critical range of temperatures than the interior and he provided theoretical arguments for this observation. Metallographic examination by Laplanche ${ }^{(21)}$ of cast irons exhibiting inverse chill also led him to an explanation of this phenomenon in terms of differential cooling, according to which wetting of the sand by the molten metal gives rise to faster cooling in the heart of the melt than at the edge. Chen $\mathrm{Pu}^{(22)}$, in an independent study, obtained the same result as Ostberg ${ }^{(18)(19)}$.

However, in the present investigation, as mentioned earlier, cooling rates were found to be almost independent of position in the ingot and so the inverse chill, when present, could not be considered to be cooling rate/temperature dependent.

\section{General discussion}

Ohno et al. ${ }^{(23)}$ suggested that the formation of inverse chill in cast iron is due to the separation of white iron from the mold wall before the formation of gray iron on the mold wall. This seems unlikely, since the conditions analysed by Ohno et al. ${ }^{(23)}$ and shown to produce chilled white iron solid were not present in our experiments and in some of the other investigators' experiments ${ }^{(20)}$ and yet inverse chill was observed.

Mg-treated nodular irons expand during eutectic solidification. From Le Chatelier's principle, the graphite eutectic reaction is expected to be retarded due to the effect of expansion-pressure if it takes place quickly, resulting in the formation of inverse chill. Recent studies $^{(13)(24)}$ of the effect of argon pressure on solidification has shown that argon pressure could have considerable effect on chill formation and the graphite nodule frequency. It was shown that the maximum nodularization is obtained at $0.15 \% \mathrm{Mg}$, which is the same composition at which the maximum amount of chill formation (minimum graphitization) takes place. However, since inverse chill did form in our melts as well as other melts ${ }^{(29)}$ solidified under $10^{-5}$ to $10^{-6}$ torr pressure, it is difficult to estimate the extent to which the expansion pressure during transformation may cause a sufficiently large pressure front for the occurrence of inverse chill. Since the liquid will relax local pressures over short times, it would appear that pressure-induced inverse chill is not a contending reason for inverse chill formation in virtually all practical cases. This leads to the following two views of the origin of inverse chill:

(i) It can be noted that both coral and compacted graphite form during the near-coupled 
growth of the gray iron eutectic cells and so, being nucleated at the outer rim of the crucible, are then propagated towards the centre, Fig. 3(a) and (b). During this period, solute partitioning between the melt and the eutectic takes place and the growth-debilitating impurities in the melt are rejected towards the eutectic front and tend to hinder the coupled growth of the outer zone (zone 1) of ingots, Fig. 3(a) and (b). These growth-debilitating impurities slowdown the growth and the interface temperature falls. Subsequently, the interface temperature can become low enough to permit the nucleation of iron-cementite $\left(\mathrm{Fe}-\mathrm{Fe}_{3} \mathrm{C}\right)$ eutectic, probably heterogeneously at the interface of an inclusion pushed ahead of the interface, due to the slowing-down the growth of the iron-graphite $(\mathrm{Fe}-\mathrm{C})$ eutectic by some of the segregating solute. Once nucleated, the ledeburite eutectic then grows faster in a coupled manner towards the thermal centre of the melt.

Also, even though only high purity, vacuum-refined melts were employed in the present investigation, in view of the lack of the detailed information on the chemical analysis of the starting materials, it is considered possible that these starting materials contained some traces of carbide stabilizing or similar impurities, left in the melt even after vacuum treatment. These trace elements when rejected by the growing solid phases of coral/compacted graphite and austenite, might hinder the nucleation as well as the growth of graphite in the eutectic, resulting in an increased undercooling and the formation of ledeburite eutectic in the central zone of an ingot.

The coupled growth of coral graphite and austenite requires a graphite branching mechanism. This branching mechanism becomes more and more ineffective as the interface temperature falls, and finally a stage is reached, when the coupled growth effectively stops. Significant coarsening of graphite occurs at the coral/compacted graphite and austenite eutectic front where growth stops, zone 2 in the photomicrographs in Figs. 3(a) and (b).

(ii) The microstructural observations in the present study indicate that graphite nodules or coarsened compacted graphite were invariably present with a surrounding austenite shell in a pearlitic or ledeburitic matrix, Figs. 3(a), (b), 4(a) and (b). Similar observations are reported in the literature ${ }^{(2)}$ for vacuum-treated pure $\mathrm{Fe}-$ $\mathrm{C}-\mathrm{Si}$ alloys. This indicates the situation of a large degree of undercooling due perhaps to a small nucleation frequency. In the above-mentioned situation, significant undercooling is possible due to the slow growth mode of spheroidal/compacted graphite as compared with that of flake graphite. The vacuumtreated melts are relatively sulphur- and oxygen-free which results in the formation of an atomically smooth or faceted interface leading to a defect-controlled spiral growth on the close-packed basal plane. This results in slower growth with more undercooling, and ultimately the formation of ledeburitic eutectic. Also spheroidal growth is said to be a completely degenerate (divorced) eutectic growth which takes place when the two phases grow in an uncoupled manner with slow carbonprecipitation as compared to the more easily accomplished coupled flake growth.

Secondly, in the process of graphite growth, the melt surrounding the coarsened/compacted or nodular graphite and directly in contact with it becomes low in carbon and gets enriched in iron due to continuous graphite precipitation. This iron-rich liquid halo then easily solidifies to an austenite shell which greatly slows down further growth of the graphite agglomerate/nodule, leading ultimately to the virtual complete ending of graphite growth after reaching a certain nodule size. All this indirectly increases the level of undercooling because the continuation of the solidification reaction to precipitate all carbon from the melt then necessitates the fresh nucleation of graphite. This increased undercooling, due to the retardation of the growth of graphite, is then responsible for favouring the formation of a carbidic eutectic in the central zone of an ingot i.e. inverse chill.

Previous investigators also seem to have noted that the conditions favouring the formation of spheroidal graphite could lead to the formation of inverse chill $^{(13)(24)(27)}$.

The occurrence of inverse chill, Figs. 3(a), (b), 4(a) and (b), could also be explained as 
follows: As the graphite growth takes place, the concentration of carbon in the melt decreases. This decreases the rate of diffusion of carbon from the melt towards the various forms of graphite, leading to the retardation of growth and hence to a greater undercooling and ultimately carbidic eutectic. The coarsening of coral/compacted graphite at the transition zone between gray and white iron portions of an ingot, Fig. 3(a) and (b) enhances this effect and still further encourages an increased undercooling and hence the formation of ledeburitic eutectic.

Finally, the following two facts suggest that there may be a natural tendency for carbideformation:

(i) It has been noted from the literature ${ }^{(28)(29)}$, that the two phases, austenite and graphite exhibit loose coupling, while the austenite/ cementite eutectic possesses a closer coupling.

(ii) Also the formation of $\mathrm{Fe}_{3} \mathrm{C}$ occurs more easily than graphite, because it does not require the complete separation of iron and carbon atoms as it forms. Graphite can form in the liquid only under conditions favourable for the almost complete separation of $\mathrm{Fe}$ and $\mathrm{C}^{(30)}$. Thus, it would appear that in any competition for formation, $\mathrm{Fe}_{3} \mathrm{C}$ should always be favoured over graphite.

\section{Conclusions}

(1) Nitrogen, hydrogen and sulphur seem to promote a gray structure without inverse chill.

(2) Inverse chill, when present, could not be considered to be cooling rate/temperature dependent.

(3) This study indicated that inverse chill could result from:

(a) slow growth of coarsened, compacted or nodular form of graphite;

(b) rejection of carbide forming/ stabilizing elements towards the centre of the remaining melt;

(c) reduction of carbon equivalent value, mainly by a reduction in siliconcontent, in a particular region of the melt; (d) the presence of oxygen or argon in the melt.

\section{Acknowledgements}

The work described is part of the foundry science and engineering programme of $\mathrm{R}$. W. Smith, in progress at Queen's University. It is supported by the Natural Science and Engineering Research Council, the National Research Council, the Department of Energy, Mines and Resources, Queen's University and private industry. The general interest and help of Dr. M. Ghoreshy in this work is gratefully acknowledged. Mr. Ding Hui, on leave from Shenyang Institute of Mechanical and Electrical Engineering was supported by the CIDAfunded Canada-China Human Development Training Programme.

\section{REFERENCES}

(1) I. C. H. Hughes and W. Oldfield: BCIRA J., 10 (1962), 475.

(2) N. Tsutsumi and Y. Matsukawa: Imono, 51 (1979), 339.

(3) C. A. Zapffe and R. L. Phebus: Trans. ASM, 41 (1949), 259.

(4) F. E. Fischer: "Inverse Chill”, Pig Iron Rough Notes (Sloss), 22, Autumn (1939), 12.

(5) H. D. Merchant: Recent Research on Cast Iron, Gordon and Breach, Science Publishers, New York, (1968), p. 1.

(6) W. Oldfield: BCIRA J., 8 (1960), 177.

(7) W. Oldfield: BCIRA J., 10 (1962), 17.

(8) J. E. Hurst: Foundry Trade J., 27 (1923), 85.

(9) T. Thielemann and A. Roder: Giessereitechnik, 16 (1970), 259.

(10) K. Kurai, Y. Kawano, N. Inoyama, S. Kanbara, M. Yamada and E. Kondo: Imono (J. Japan Foundrymen's Society), 43 (1971), 869.

(11) H. K. Park: Ph. D. Thesis, Department of Metallurgical Engineering, The University of Wisconsin, Madison, USA., (1981).

(12) A. Boyles: The Structure of Cast Iron, ASM, Cleveland, Ohio, (1947).

(13) T. Okamoto, X. Huang and A. Kagawa: Metal Science, 18 (1984), 169.

(14) H. W. Dietert and E. E. Woodliff: AFS. Trans., 48 (1940), 393.

(15) C. E. Bales and F. McCarthy: American Foundryman, 6 (1944), 2.

(16) P. Gallinaro: International Foundry Congress, Florence, Paper No. 10, (1954).

(17) A. Boyles: AFS Trans., 46 (1938), 297.

(18) G. Ostberg: J. Iron and Steel Inst., 189 (1958), 57.

(19) G. Ostberg and C. E. Gustafsson: Gjuteriet, 48 (1958), 8. 
(20) B. Dhindaw and J. D. Verhoeven: Met. Trans., 11A (1980), 1049.

(21) H. Laplanche: Met. Constr. Mecan, 103 (1971), 339.

(22) C. Chen Pu: Chzhugun, 9 (1957), 1, Abst. J. Metallurgy, No. 5-6 (1958), 92.

(23) A. Ohno, T. Motegi and N. Kobayashi: Solidification Technology in the Foundry and Cast House, Coventry, England, Conf., (1980), 288.

(24) S. Yamamoto, B. Chang, Y. Kawano, R. Ozaki and Y. Murakami: Met. Sci., 9 (1975), 360.

(25) J. Keverian, H. F. Taylor and J. Wulff: American Foundryman, 23 (1953), 85.

(26) S. V. Subramanian et al.: Iron and Steel Magazine, March (1980), 18.

(27) M. Doi, S. Nishi and Y. Ueda: Imono, 45 (1973), 871.

(28) M. Hillert and V. V. Subba Rao: The Solidification of
Metals, I.S.I.P. 110, London, (1968), p. 204.

(29) R. J. Brigham, G. R. Purdy and J. S. Kirkaldy: International Conference on Crystal Growth, Boston, (1966), p. 161.

(30) F. Compomanes and R. Goller: AFS Trans., 83 (1975), 55.

(31) R. D. Bhavsar, N. W. Blake, M. Ghoreshy and R. W. Smith: Proceedings of the Third International Symposium on the Physical Metallurgy of Cast Iron, (Stockholm, Sweden, August 29-31, 1984), Elsevier Science Publishing Company, Inc., New York, USA, (1985), p. 77.

(32) R. D. Bhavsar: Ph. D. Thesis, Department of Metallurgical Engineering, Queen's University, Kingston, Ontario, Canada, (1986). 